\title{
NOTES
}

\section{RADIO TRACKING MOUNTAIN BLUEBIRDS VISITING NEIGHBORS' NESTS}

ALISHA RITCHIE and MYRNA PEARMAN, Ellis Bird Farm, Box 5090, Lacombe, Alberta, T4L 1W7, Canada; ralisha2309@gmail.com, mpearman@ellisbirdfarm.ca

All three species of North American bluebirds are secondary cavity nesters that readily accept nest boxes. Typically, all three are socially monogamous, with a single male and a single female defending a territory against intruding conspecifics and alone raising their offspring (Guinan et al. 2008, Gowaty and Plissner 2015, Johnson and Dawson in press). Both parents provision nestlings for 17-22 days, and the young continue to rely on the parents for protection and food for several weeks post-fledging (Guinan et al. 2008, Gowaty and Plissner 2015, Johnson and Dawson in press). Pairs that raise a first brood early enough in the season usually make a second attempt (Guinan et al. 2008, Gowaty and Plissner 2015, Johnson and Dawson in press).

Visits to nests by individuals other than the breeding pair have been documented in all three species. In some cases, these visitors, often young males from a previous nesting, help rear offspring. Such "cooperative breeding" has been most widely documented in the Western Bluebird (S. mexicana), although helping behavior occurs in some populations but not others (Dickinson et al. 1996), perhaps because of a female-biased sex ratio resulting in local competition for mates (Guinan et al. 2008). Cooperative breeding is very rare in the Eastern Bluebird (S. sialis) and Mountain Bluebird (S. currucoides). In the former, there are a few reports of either juvenile helpers entering the nest cavity when adults are feeding later broods (Pinkowski 1975) or adult helpers, usually the second-year son of current breeders, irregularly helping feed young (Pinkowski 1976).

There are three published accounts of cooperative breeding in the Mountain Bluebird (Johnson and Dawson in press). In two cases, juveniles from the parents' first brood of the season were suspected of helping feed the parents' second brood (Mills 1931, Johnson and Dawson in press). In the third case, two pairs of adults attended a single nest. Both females fed the young, as did one male who also repeatedly chased the other male away (Cannings et al. 1987).

In other species of secondary cavity nesters, such as the Common Goldeneye (Bucephala clangula), Collared Flycatcher (Ficedula albicollis), and Tree Swallow (Tachycineta bicolor), cases of conspecific visitation at active nests have been described as individuals prospecting for future nesting sites (Reed et al. 1999). Prospecting is thought to allow a bird to assess the habitat's quality so it can select an optimal territory and nest site for the following breeding season (Doligez et al. 1999, 2004a, b, Reed et al. 1999, Kivelä et al. 2014). Competition among secondary cavity nesters for limited nest sites may also drive prospecting behavior (Brawn 1984, Lombardo 1987). Juvenile Western Bluebirds have been observed to defend inactive nest boxes adjacent to their natal nest box, perching on or near the box but not roosting in it (Brawn 1984).

Instances of conspecific nest visitation, be it the result of rare cooperative breeding, prospecting for the future, or for some other reason, are undoubtedly underreported because documenting such behavior requires that marked breeding pairs be monitored nearly continuously. We describe here two instances of conspecific nest visitation in the Mountain Bluebird documented by means of radio frequency identification (RFID) technology during a study of parental provisioning behavior.

Our study took place near Lacombe, central Alberta, Canada $\left(52^{\circ} 28^{\prime} 06^{\prime \prime} \mathrm{N}\right.$, $113^{\circ} 44^{\prime} 13^{\prime \prime} \mathrm{W}$, elevation $855 \mathrm{~m}$ above sea level). Since 1982, the staff of Ellis Bird 


\section{NOTES}

Farm have monitored bluebird boxes located in habitat appropriate for the Mountain Bluebird within an area (a "management area") of approximately $250 \mathrm{~km}^{2}(16 \times 16$ $\mathrm{km})$. Since our monitoring of the Mountain Bluebird at Ellis Bird Farm began in 1982, we had observed no instances of a Mountain Bluebird visiting a neighbor's nest until we began deploying RFIDs in 2018.

RFID technology entails the use of a passive integrated transponder (PIT) tag and a receiving antenna. Each PIT tag contains a unique 15-digit identification number, which is logged along with the time and date (called an "event") by the antenna each time the tag comes within range of the antenna (approximately $2 \mathrm{~cm}$ ). In our study we equipped nest boxes with an antenna and Mountain Bluebirds with PIT tags. Thus the antenna logged an event each time a bird entered, exited, or perched at the next box's entrance. Since both entrances and exits log an event, and long strings of events are logged when a bird is perched at the entrance, we counted all events logged within a one-minute period as one "visit." To attach PIT tags, we 3-D printed plastic leg bands each with a compartment for a PIT tag $8 \mathrm{~mm}$ long (Figure 1). A circular antenna, also generated by a 3-D printer and painted the same color as the nest box, was secured to the front of the nest box around the entrance (Figure 2). The unit was powered by a 12 -volt battery.

In 2018 , we set up RFID units at 11 nest boxes located within a $70-\mathrm{km}^{2}(8.5 \times$ $8.5 \mathrm{~km}$ ) portion of the management area (Figure 3). We monitored eight first nest attempts and five second and/or late nest attempts at these boxes. At two nest boxes, both the first and second nesting were monitored. Nest boxes with RFID units were an average $5.1 \mathrm{~km}$ apart (range $268 \mathrm{~m}$ to $9.7 \mathrm{~km}$ ). Where feasible, both sexes at these boxes were banded with PIT tags, although at some nests only the female was banded because the male was either not present or would not enter the trap-set nest box. We banded a total of 20 adult birds with PIT tags. All 48 nestlings at boxes
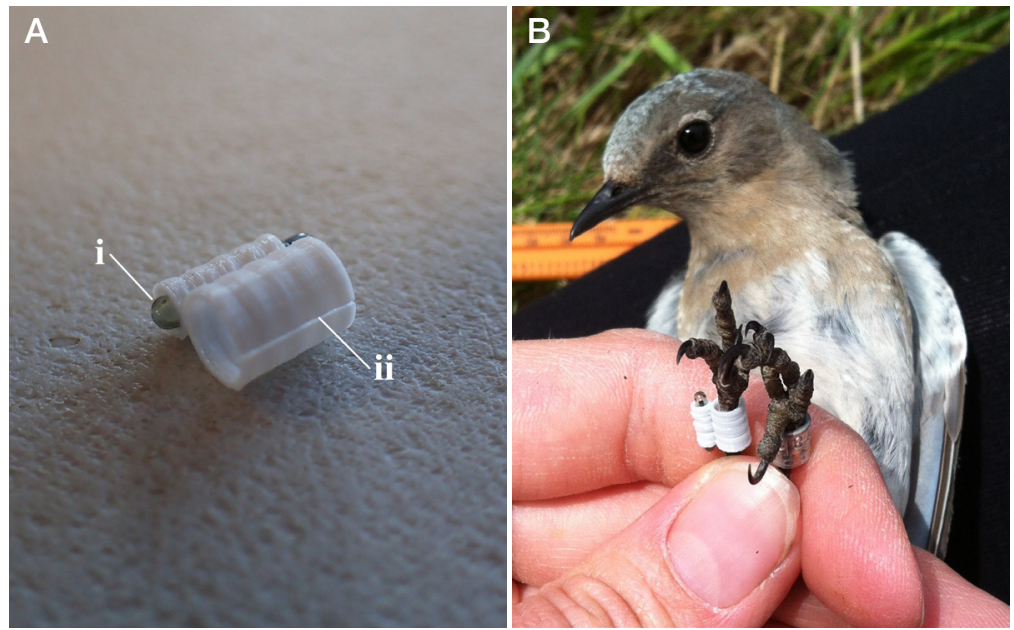

Figure 1. Radio-frequency identification (RFID) used in our study of the Mountain Bluebird. (A) Close-up of 3-D-printed color leg band showing (i) the passive integrated transponder (PIT) inserted and (ii) the slit allowing for banding with a plastic-color-band spreader. (B) White leg band with the RFID placed on the right tarsus of a female Mountain Bluebird.

Photos by Myrna Pearman (A) and Alisha Ritchie (B) 


\section{NOTES}
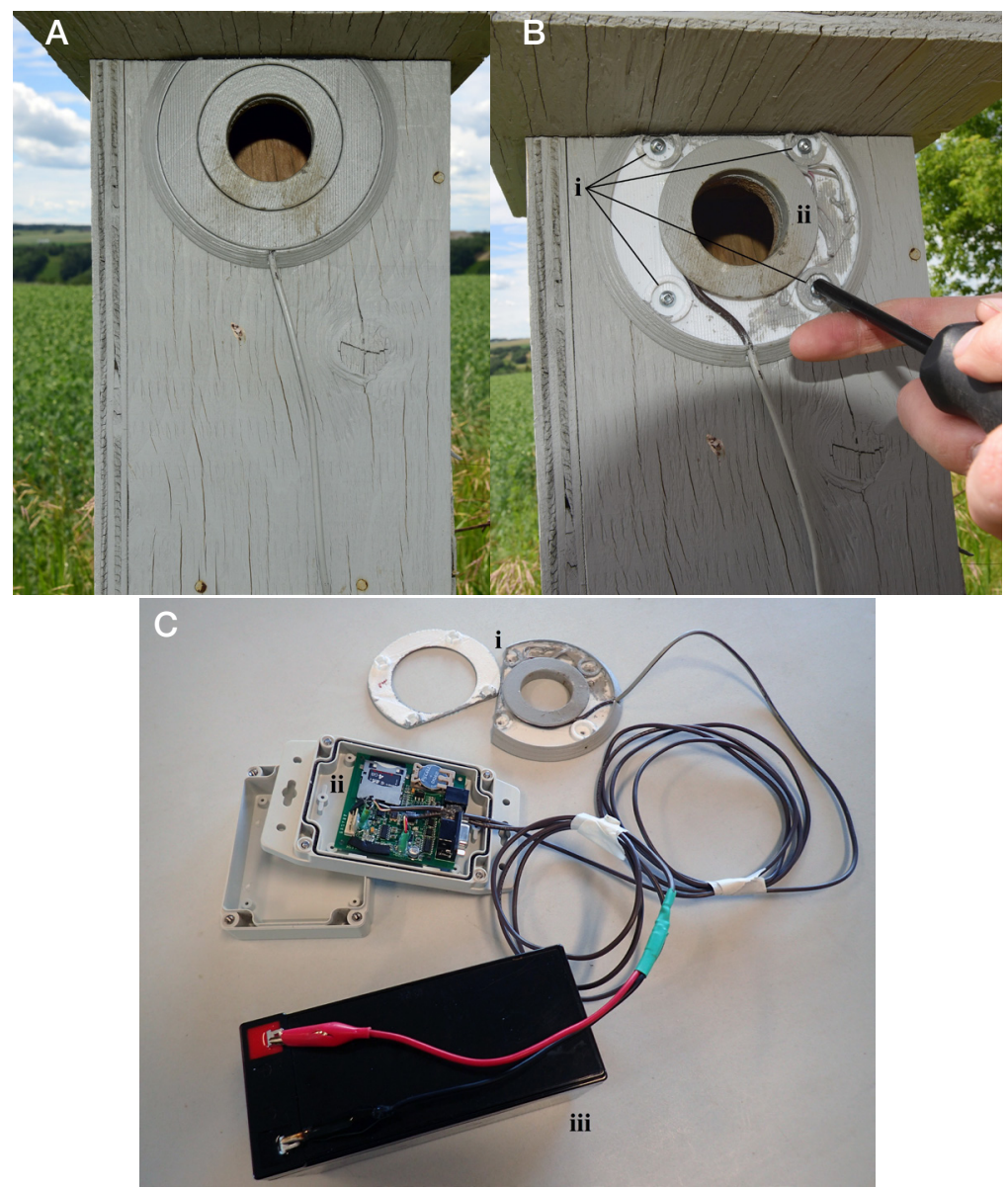

Figure 2. (A) 3-D-printed antenna case at entrance of nest box with clip-on cap in place, and (B) removed to show (i) the screws used to secure the antenna to the nest box and (ii) the spool around which copper wire was wound to form the antenna. (C) All components needed for the RFID to function, including (i) the antenna in a 3-D-printed case, (ii) the RFID logger with Secure Digital (SD) card for memory storage in a water-tight case, and (iii) the 12-volt battery to power the system.

Photos by Myrna Pearman

monitored were banded with a PIT tag when they were 8-16 days old, and all but one of the banded nestlings successfully fledged.

The RFIDs recorded two instances of males visiting the next nearest neighboring box with an active Mountain Bluebird nest. These two cases involved visitation between the two closest pairs of nest boxes (146-145 and 10.78-16.03, Figure 3) in the study area, which were located $<300 \mathrm{~m}$ apart. The next closest pair of active nest boxes (125-148, Figure 3) were $390 \mathrm{~m}$ apart, but the nest in one of those boxes 


\section{NOTES}

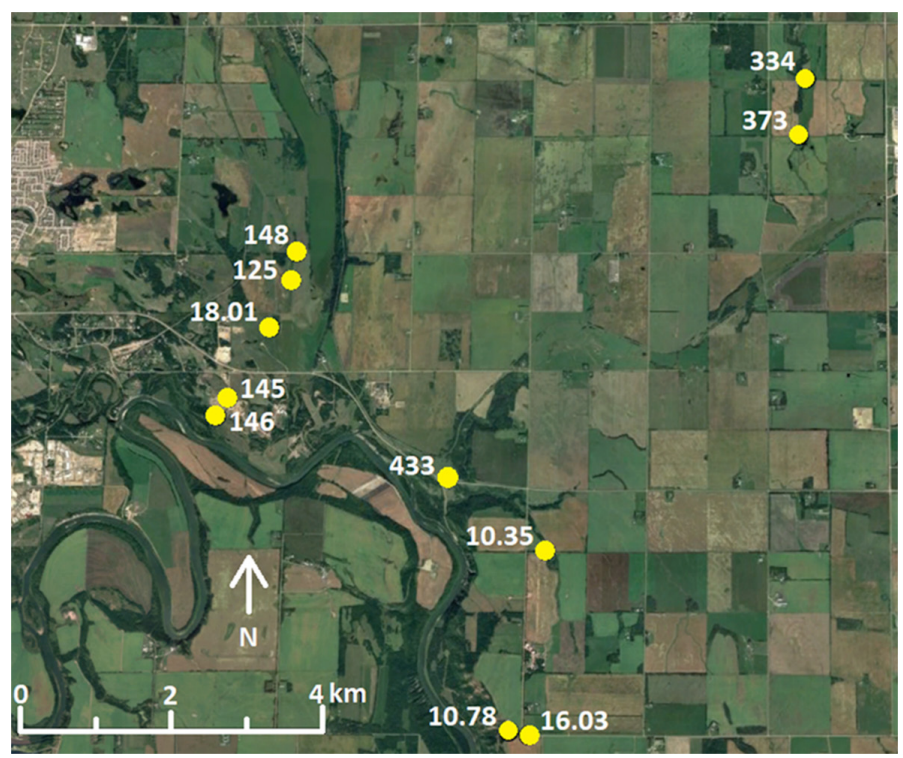

Figure 3. Study area at Ellis Bird Farm, Lacombe, Alberta. Yellow circles, locations of all nest boxes monitored with RFID units within the management area of nest boxes monitored by Ellis Bird Farm. Numbers next to each point represent the nest box's identification number.

failed when the nestlings were six days old. The next closest pair of boxes (373-334, Figure 3) both of which had successful nests were located $812 \mathrm{~m}$ apart.

In the first instance, a second-year male (V2M), which was provisioning a second or late brood in a nest box he controlled, visited a neighboring nest box $287 \mathrm{~m}$ away on three separate days, 28 June, 29 June, and 16 July 2018, when nestlings at the neighboring nest were zero (hatch day), one, and 18 days old, respectively. No male was observed at the neighboring nest throughout the nestling period. A male was seen multiple times at this nest up until June 14 but was not seen when the nest was rechecked on June 22 or any time thereafter, including extended (>30 min) monitoring after nestlings had hatched. We cannot rule out polygyny because we did not observe a male at each of these nest boxes on the same day.

On 28 June, V2M made a total of 38 visits between 10:19 and 20:31. It is not known whether V2M simply perched at the entrance or entered the box. He made no visits to his own nest that day, even though his own nestlings were four days old. On 29 June, V2M made six visits between 05:45 and 07:14, during which time he again made no visits to his own nest. At 8:30, he returned to his own nest and subsequently made 83 visits until his last activity at $22: 31$. On 16 July 2018, the day after the nestlings at his own nest fledged, he made a single visit to the neighboring nest at 14:02. At the time of V2M's first visit to the neighboring nest, the resident female made a visit six seconds before and seven seconds after V2M's visit. After that, however, only $10.9 \%$ of the visits by V2M and the resident female were within the same minute. All hatched young were observed in the nest after V2M's last visit on 29 June. On 9 July, however, when we banded them, only five of the seven nestlings remained, and subsequently fledged. 


\section{NOTES}

In the second instance, a juvenile fledged from a first brood (VJM) made a single visit to a neighboring box $267 \mathrm{~m}$ away, which contained 18-day-old nestlings. The visit was at 7:28 on 1 August 2018. The resident male at that nest made a visit 68 minutes before and 44 minutes after VJM's activity and thus may never have seen VJM. The resident female of the nest made a visit 15 minutes before and 23 seconds after VJM's visit, which is possibly why there was only a single visit. We do not know, however, if the female had any interaction with the juvenile male.

Our results indicate that Mountain Bluebirds of different ages do visit the territories and nest cavities occupied by other individuals. Because the technology used in this study records only the presence/absence of individuals at a nest site, we do not know the behaviors of the two bluebirds during their visits to the two nests and so cannot infer the visits' purpose. However, given the number of visits, the length of time over which visits were made, and that there was no activity by V2M at his own nest even though it contained nestlings, it is possible that V2M may have provided the young in the visited box with some kind of parental care, such as feeding them. Since extra-pair mating is common in the Mountain Bluebird (O'Brien and Dawson 2011, Johnson and Dawson in press), it is possible that V2M fathered one or more of the nestlings in the box visited. The possibility that V2M was providing parental care at the nest of an extra-pair mate is intriguing because males feeding young of extra-pair mates has rarely, if ever, been documented in bluebirds, potentially because cuckolded males are usually present to drive off the extra-pair father. In this case, however, the resident male had disappeared. Experiments in which resident males are held temporarily in captivity while the response of nearby males is observed could be enlightening, especially if combined with paternity analyses. Another possibility is that this male entered the neighboring territory to seek extra-pair copulations or some other purpose and, when encountering nestlings, was stimulated to provision them instead of those in his own nest, at least for a time.

The single visit by the recent fledgling (VJM), may have involved prospecting behavior, although this male was not detected at other nests in the area (the next nearest nest with an RFID was $2.4 \mathrm{~km}$ away from his natal nest box). After fledging, juvenile Western Bluebirds from first broods have been observed to defend boxes near their natal nest box (Brawn 1984). An attempt at such defense could account for VJM visiting the nest box nearest his natal box. But finding it occupied he was unable to defend it and moved on. Alternatively, some fledglings appear to leave their natal territories, whether voluntarily or after being driven away by their parents (Power and Lombardo 1996), to join other bluebirds in post-breeding flocks. VJM may have begun searching for a post-breeding flock and was attracted to the begging activity at the nearby nest.

In conclusion, we documented for the first time that Mountain Bluebirds visit neighboring nest cavities controlled by other individuals. Because the sample of nests and individuals that were monitored was small, yet we documented two examples of such visitation, it is likely part of this species' behavioral repertoire. Further examination of this behavior in the Mountain Bluebird is warranted to determine how routine it is in the species, how its frequency varies by sex and age, and its function.

Funding support for this research was provided by the Red Deer and District Community Foundation through the Conservation of Bluebirds, Swallows and Other Native Cavity-Nesting Birds Fund. Our thanks to Leo de Groot, Maureen Carey, Scott Johnson, and Pat Gowaty for their review and comments.

\section{LITERATURE CITED}

Brawn, J. D. 1984. Defense of nest boxes by Western Bluebirds during the postbreeding period. Condor 86:494-495; doi 10.2307/1366842.

Cannings, R. A., Cannings, R. J., and Cannings, S. G. 1987. Birds of the Okanagan Valley, British Columbia. Royal Br. Columbia Mus., Vancouver. 


\section{NOTES}

Dickinson, J. L., Koenig, W. D., and Pitelka, F. A. 1996. Fitness consequences of helping behavior in the Western Bluebird. Behav. Ecol. 7:168-177; doi 10.1093/beheco/7.2.168.

Doligez, B., Danchin, E., Clobert, J., and Gustafsson, L. 1999. The use of conspecific reproduction success for breeding habitat selection in a non-colonial, hole-nesting species, the Collared Flycatcher. J. Anim. Ecol. 68:1193-1206; doi 10.1046/j.1365-2656.1999.00362.x.

Doligez, B., Pärt, T., Danchin, E., Clobert, J., and Gustafsson, L. 2004a. Availability and use of public information and conspecific density for settlement decisions in the Collared Flycatcher. J. Anim. Ecol. 73:75-87; doi 10.1111/j.13652656.2004.00782.x.

Doligez, B., Pärt, T., and Danchin, E. 2004b. Prospecting in the Collared Flycatcher: Gathering public information for future breeding habitat selection? Anim. Behav. 67:457-466; doi 10.1016/j.anbehav.2003.03.010.

Gowaty, P. A., and Plissner, J. H. 2015. Eastern Bluebird (Sialia sialis), in The Birds of North America (A. F. Poole, ed.), no. 381, version 2.0. Cornell Lab. Ornithol., Ithaca, NY; doi 10.2173/bna.381.

Guinan, J. A., Gowaty, P. A., and Eltzroth, E. K.. 2008. Western Bluebird (Sialia mexicana), in The Birds of North America (A. F. Poole, ed.), no. 510, version 2.0. Cornell Lab. Ornithol., Ithaca, NY; doi 10.2173/bna.510.

Johnson, L. S., and Dawson, R. D. In press. Mountain Bluebird (Sialia currucoides), in The Birds of North America (P. G. Rodewald, ed.), version 3.0. Cornell Lab. Ornithol., Ithaca, NY.

Kivelä, S. M., Seppänen, J. T., Ovaskainen, O., Doligez, B., Gustafsson, L., Mönkkönen, M., and Forsman, J. T. 2014. The past and the present in decisionmaking: The use of conspecific and heterospecific cues in nest site selection. Ecology 95:3428-3439; doi 10.1890/13-2103.1.

Lombardo, M. P. 1987. Attendants at Tree Swallow nests. II. The exploratory-dispersal hypothesis. Condor 89:138-149; doi 10.2307/1368768.

Mills, E. A. 1931. Bird Memories of the Rockies. Houghton Mifflin, Boston.

O'Brien, E. L., and Dawson, R. D. 2011. Plumage color and food availability affect male reproduction success in a socially monogamous bird. Behav. Ecol. 22:66-72; doi 10.1093/beheco/arq167.

Pinkowski, B. C. 1975. Yearling male Eastern Bluebird assists parents in feeding young. Auk 92:801-802; doi 10.2307/4084794.

Pinkowski, B. C. 1976. Further observation on a family of Eastern Bluebirds. BirdBanding 47:160-161; doi 10.2307/4512216.

Power, H. W., and Lombardo, M. P. 1996. Mountain Bluebird (Sialia currucoides), in The Birds of North America (A. Poole and F. Gill, eds), no. 222. Acad. Nat. Sci., Philadelphia; doi 10.2173/bna.222.

Reed, J. M., Boulinier, T., Danchin, E., and Oring, L. W. 1999. Informed dispersal: Prospecting by birds for breeding sites, in Current Ornithology, (V. Nolan, Jr., E. D. Ketterson, and C. F. Thompson, eds.), vol.15, pp. 189-259. Kluwer Academic/Plenum, New York; doi 10.1007/978-1-4757-4901-4_5.

Accepted 4 March 2019 